\title{
THE ELUTION OF IONS THROUGH FIELD AND LABORATORY SNOWPACKS
}

\author{
by
}

Sotiris Tsiouris, Christopher E. Vincent, Trevor D. Davies and Peter Brimblecombe

(School of Environmental Sciences, University of East Anglia, Norwich NR4 7TJ, England)

\section{ABSTRACT}

It has been recognised for many years that the first fraction of meltwater from a melting snowpack contains a much higher concentration of ions than that of the bulk (or average) snow of which the pack is comprised (Foster 1978, Johannessen and Henriksen 1978). This process leads to the so called "acid flush" in the spring and can have severe ecological effects on lakes and streams (Hagen and Langeland 1973, Leivestad and Muniz 1976, National Research Council of Canada 1981). We have studied elution of ions through a snowpack on Folgefonna near Bergen, Norway, and in the laboratory. In the field we collected meltwater samples at hourly intervals for a period of $4 \mathrm{~d}$ at the start of the melt season, and analyzed them for $\mathrm{pH}$, $\mathrm{NO}_{3}^{-}, \mathrm{SO}_{4}^{2-}, \mathrm{Cl}^{-}, \mathrm{Na}^{+}, \mathrm{Mg}^{2+}, \mathrm{Ca}^{2+}$ and $\mathrm{K}^{+} .2 \mathrm{~m}$ cores were also collected at the beginning and end of the experiment in order to study bulk changes in snow composition. The meltwaters showed a diurnal cycle with high ionic concentrations around noon, with $\mathrm{NO}_{3}^{-}$and $\mathrm{SO}_{4}^{2-}$ levels rising by factors of up to four and six-fold compared to the average concentrations on the first day. $\mathrm{Cl}^{-}$levels peaked much later, after the $\mathrm{NO}_{3}^{-}$and $\mathrm{SO}_{4}^{2-}$ levels had decreased, and only reached 2.3 times their lowest concentrations. $\mathrm{pH}$ values were strongly correlated with $\mathrm{NO}_{3}^{-}$and $\mathrm{SO}_{4}^{2-}$ levels, suggesting that a significant proportion of these anions were in the form of strong acids.

The laboratory experiments involved slow melting of snow samples collected in the Cairngorm mountains, Scotland, and also showed that $\mathrm{NO}_{3}^{-}$and $\mathrm{SO}_{4}^{2-}$ (and also $\mathrm{Mg}^{2+}$ and $\mathrm{K}^{+}$) ions were removed from the snow preferentially whilst $\mathrm{Na}^{+}$and $\mathrm{Cl}^{-}$tended to remain longer. The position of $\mathrm{H}^{+}$within the ion elution sequence is unclear due to uncertainties in the absolute determination of $\mathrm{pH}$ in the field measurements, but the laboratory experiments confirm the differential rates of elution shown in the Norwegian snowpack and reaffirms its importance in the acidification of streams during spring.

\section{INTRODUCTION}

Previous work on Folgefonna (Davies and others 1982) has shown that not only are the majority of ions removed from the overlying snow and firn early in the melt sequence (fractionation), but that some ionic species are removed preferentially (preferential elution). This suggests that this latter process could result in the early removal of hydrogen ions (relative to other cations), together with $\mathrm{SO}_{4}^{2-}$ and $\mathrm{NO}_{3}^{-}$ions, as strong acids. However the results from the previous study are difficult to interpret as they come from a $60 \mathrm{~m}$ core which, in the upper $20 \mathrm{~m}$ at least, represents a combination of ice from which the majority of ions would have been removed during a previous melt season and the meltwater percolating downwards from the snow melting near the surface. The experiments described here were designed to look at the processes of preferential elution and fractionation under more controlled conditions, both in the field and in the laboratory.

\section{METHODOLOGY}

\subsection{Field experiments}

These were performed near the summit of Folgefonna (altitude $1600 \mathrm{~m}$ ) close to the site used by Davies and others (1982) in their coring work during 1981 (Fig.1). The

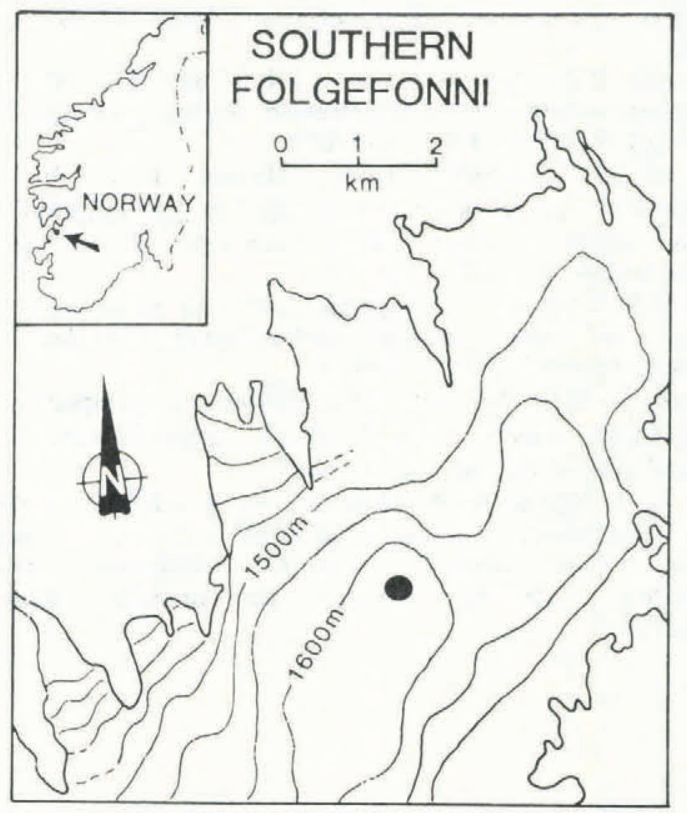

Fig.1. Field melt experiments were undertaken on Folgefonna, situated close to the west coast of Norway, at the location indicated.

1983 melt season was particularly late and, compared with 1981, little ablation of the winter snow had occurred before the beginning of these experiments. A pit $2.5 \mathrm{~m}$ deep was dug through the surface snow of the ice cap and short horizontal tunnels (referred to as "nests"), $50 \mathrm{~cm}$ long and $30 \mathrm{~cm}$ square and of fset from each other horizontally, were dug into the side of the pit at depths of $0.2,0.4,0.5,0.9$ and $1.8 \mathrm{~m}$. The roofs of these tunnels were convexed, and a funnel and clean collecting bottle placed beneath the lowest point of the roof of each to collect meltwater percolating down through the snowpack. Only the results from the nest at the depth of $1.8 \mathrm{~m}$ are presented here. During the day on which the nest was constructed (11 July) no meltwater was collected although from 8 to $10 \mathrm{~cm}$ of surface ablation was measured during the day. This was thought to be due to the meltwater being carried away along previously established channels. The next morning (12 July), a heat lamp $(275 \mathrm{~W})$ was mounted $30 \mathrm{~cm}$ above the snow directly over the nest to establish new meltwater channels and after about $1 \mathrm{~h}$ (during which time 2 to $3 \mathrm{~cm}$ of ablation had occurred under the lamp) meltwater reached the nest below. The lamp was removed and meltwater was collected at the nest for $4 \mathrm{~d}$. Samples were collected hourly during daylight hours while overnight a large container was left to give an integrated sample. Measurements usually commenced at about $10.00 \mathrm{~h}$ each morning. $\mathrm{pH}$ was measured on site within a few hours of collection using a Corning $113 \mathrm{pH}$ meter and the samples were stored at $\sim 0^{\circ} \mathrm{C}$ in snow-pits, before being returned to the laboratory where they were stored at $3{ }^{\circ} \mathrm{C}$ for about 8 weeks before analysis.

In addition to the melt samples from the nests, snow 
cores $2 \mathrm{~m}$ long were taken within $5 \mathrm{~m}$ of the location of the melt experiment. Three cores (A, B and C) were extracted on 8 July, the first day the expedition was at the melt site, and two more (D and E) were taken on 15 July, as the melt experiment was concluded. These snow cores were sectioned, labelled and bagged, then stored in a deep snow-pit until the conclusion of the expedition when they were lifted by helicopter to a nearby helipad and transferred to a chest freezer at $-18^{\circ} \mathrm{C}$. They were then returned frozen to the UK and kept in a cold store until immediately before analysis.

Sample handling in the laboratory was carried out under clean conditions, using a laminar flow cabinet and stainless steel or PTFE-coated tools. Melted core samples and meltwater from the nests were filtered through $0.22 \mu \mathrm{m}$ cellulose acetate filters before analysis. Anions were measured using a Dionex Model 12 ion chromatograph with detection limits of better than $0.2 \mu \mathrm{eq} \mathrm{I}^{-1}(\sim 0.01 \mathrm{ppm})$ for $\mathrm{SO}_{4}^{2-}, \mathrm{NO}_{3}^{-}$and $\mathrm{Cl}^{-}$. Precision was better than $\pm 3 \%$. Cation concentrations were determined using a Pye Unicam SP9 atomic absorption spectrophotometer with detection limits and precision for $\mathrm{Na}^{+}, \mathrm{Mg}^{2+}, \mathrm{Ca}^{2+}$, and $\mathrm{K}^{+}$similar to those of the anions. No ammonium determinations were made.

The measurement of $\mathrm{pH}$ has remained the least satisfactory part of the analytical procedure and, whereas the precision of these $\mathrm{pH}$ measurements is to within $0.1 \mathrm{pH}$ units, their accuracy is likely to be very much less. The field measurements of $\mathrm{pH}$ involved manual stirring and calibration against strong buffers, whereas recent work by McQuaker and others (1983) has indicated that accurate laboratory $\mathrm{pH}$ measurements should be made using quiescent samples and that calibration should be against strong acid solutions. They suggest that field determinations of $\mathrm{pH}$ are unlikely to be better than 0.1 or $0.2 \mathrm{pH}$ units.

\subsection{Laboratory experiments}

Snow was collected from a fresh drift (within $24 \mathrm{~h}$ of the end of the snowfall) in the Cairngorm mountains, Scotland and returned to a cold store at $-4{ }^{\circ} \mathrm{C}$. Although the snow drift was apparently uniform and structureless, five samples taken at random from amongst the snow collected showed considerable differences in ionic concentrations $\left(\mathrm{SO}_{4}^{2-}\right.$ had a mean of $44 \mu \mathrm{eq} \mathrm{I}^{1}$ and a standard deviation of $43 \mu$ eq $\mathrm{r}^{1}$ ). For each melt experiment approximately $8 \mathrm{~kg}$ of the snow was homogenized with an overhead stirrer using only PTFE-coated tools, until chemical analyses of random samples were the same (within the repeatability of the analysis technique, usually better than $3 \%$ ).

The bulk concentration ratio of $\mathrm{Na}^{+}$and $\mathrm{Mg}^{2+}$ of 3.9:1 (in $\mu$ eq $\mathrm{r}^{-1}$ ) is very close to that of sea-water as are the concentration ratios of $\mathrm{Na}^{+}, \mathrm{Cl}^{-}$and $\mathrm{SO}_{4}^{2-}$, with little evidence of excess $\mathrm{SO}_{4}^{2-}$ due to pollutant sources. The very low $\mathrm{NO}_{3}^{-}$values are also indicative of a relatively clean air-mass source for this snow.

The experiments were carried out in a simple cylindrical container made from PVC plastic, with a base

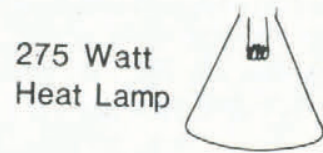

Perspex

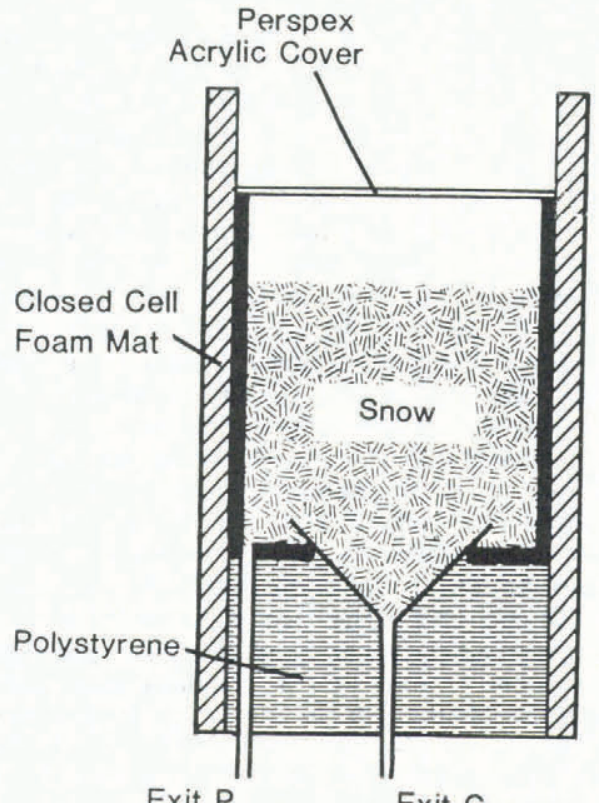

Exit $P$

Exit $\mathrm{C}$

Fig.2. Experimental configuration for the laboratory melt experiments. The inner cylinder has a diameter of $25 \mathrm{~cm}$ and a height of $30 \mathrm{~cm}$.

TABLE I. AVERAGE (a), MAXIMUM (b) AND MINIMUM (c) CONCENTRATIONS IN $\mu$ eq $\mathrm{l}^{-1}$ OF THE MAJOR IONS IN FOUR SNOW CORES. A and B were collected on 8 July, and D and E on the 15 July. The average depletion of each ion from the cores over this period is also shown and a rank order of preferential elution suggested.)

\begin{tabular}{|c|c|c|c|c|c|c|c|}
\hline $\begin{array}{l}\text { Ion } \\
\text { species }\end{array}$ & & A & B & D & $\mathrm{E}$ & $\begin{array}{c}\text { Decrease } \\
\%\end{array}$ & $\begin{array}{l}\text { Rank } \\
\text { order }\end{array}$ \\
\hline $\mathrm{Cl}^{-}$ & $\begin{array}{l}\text { (a) } \\
\text { (b) } \\
\text { (c) }\end{array}$ & $\begin{array}{l}33.5 \\
66.3 \\
10.7\end{array}$ & $\begin{array}{r}28.8 \\
61.2 \\
6.5\end{array}$ & $\begin{array}{r}13.0 \\
19.7 \\
5.4\end{array}$ & $\begin{array}{r}15.5 \\
26.5 \\
9.0\end{array}$ & 56.4 & 6 \\
\hline $\mathrm{NO}_{3}^{-}$ & $\begin{array}{l}\text { (a) } \\
\text { (b) } \\
\text { (c) }\end{array}$ & $\begin{array}{l}5.8 \\
8.2 \\
2.4\end{array}$ & $\begin{array}{r}8.1 \\
33.4 \\
1.8\end{array}$ & $\begin{array}{l}1.1 \\
2.3 \\
0.6\end{array}$ & $\begin{array}{l}1.3 \\
2.1 \\
0.6\end{array}$ & 82.6 & 2 \\
\hline $\mathrm{SO}_{4}^{-}$ & $\begin{array}{l}\text { (a) } \\
\text { (b) } \\
\text { (c) }\end{array}$ & $\begin{array}{r}5.6 \\
13.1 \\
2.3\end{array}$ & $\begin{array}{r}4.0 \\
10.0 \\
2.1\end{array}$ & $\begin{array}{l}1.9 \\
2.7 \\
1.5\end{array}$ & $\begin{array}{l}2.3 \\
3.3 \\
0.6\end{array}$ & 56.8 & 5 \\
\hline $\mathrm{Na}^{+}$ & $\begin{array}{l}\text { (a) } \\
\text { (b) } \\
\text { (c) }\end{array}$ & $\begin{array}{r}10.4 \\
23.9 \\
2.6\end{array}$ & $\begin{array}{r}10.4 \\
26.5 \\
1.7\end{array}$ & $\begin{array}{l}4.8 \\
7.4 \\
1.3\end{array}$ & $\begin{array}{r}6.1 \\
11.3 \\
3.5\end{array}$ & 48.1 & 7 \\
\hline $\mathrm{Ca}^{2+}$ & $\begin{array}{l}\text { (a) } \\
\text { (b) } \\
\text { (c) }\end{array}$ & $\begin{array}{r}8.0 \\
14.0 \\
2.0\end{array}$ & $\begin{array}{r}6.5 \\
20.4 \\
1.5\end{array}$ & $\begin{array}{l}0.5 \\
2.0 \\
0.0\end{array}$ & $\begin{array}{l}1.0 \\
2.5 \\
0.5\end{array}$ & 90.4 & 1 \\
\hline $\mathrm{Mg}^{2+}$ & $\begin{array}{l}\text { (a) } \\
\text { (b) } \\
\text { (c) }\end{array}$ & $\begin{array}{l}1.6 \\
4.9 \\
0.8\end{array}$ & $\begin{array}{l}1.6 \\
4.9 \\
0.0\end{array}$ & $\begin{array}{l}0.6 \\
0.8 \\
0.0\end{array}$ & $\begin{array}{l}0.7 \\
0.8 \\
0.0\end{array}$ & 62.2 & 4 \\
\hline $\mathrm{K}^{+}$ & $\begin{array}{l}\text { (a) } \\
\text { (b) } \\
\text { (c) }\end{array}$ & $\begin{array}{l}1.8 \\
3.3 \\
0.5\end{array}$ & $\begin{array}{l}2.3 \\
8.7 \\
0.5\end{array}$ & $\begin{array}{l}0.5 \\
1.0 \\
0.0\end{array}$ & $\begin{array}{l}0.3 \\
0.8 \\
0.3\end{array}$ & 80.0 & 3 \\
\hline
\end{tabular}


consisting of a central funnel collector and an outer concentric collection region (Fig.2). The two collecting points for meltwater were used to attempt to differentiate between meltwater which percolated down through the snow and that which either ran down the inside surface of the cylinder or was melted directly by the cylinder (due to the different radiation absorption properties of snow and plastic). The experiments were carried out in a cold room set at $-2{ }^{\circ} \mathrm{C}$ (although air temperatures fluctuated $\pm 2{ }^{\circ} \mathrm{C}$ on a time scale of a few minutes) with the cylinder wrapped in a closed-cell foam mat to increase the insulation and reduce edge melting effects. Melting was by a $275 \mathrm{~W}$ infrared lamp suspended between 20 and $30 \mathrm{~cm}$ above the snow surface. Sample treatment and analyses were as for the field samples.

\section{RESULTS AND DISCUSSION}

\subsection{Field experiments: snow cores}

The cores showed great variability between sites that were only $1 \mathrm{~m}$ apart, as was observed by Brimblecombe and others (1985). The ion concentrations of the first three cores, A, B and C, collected on 8 July, generally increased with depth but showed considerable variations in concentration (a factor of 2 to 3 ) over distances of a few centimetres. Table I lists the volume-weighted average concentrations of the major anions and cations in cores A and $\mathrm{B}$ and also in the two cores, D and E, which were collected $7 \mathrm{~d}$ later. The maximum and minimum concentrations are also given. Figure 3 shows the profiles of $\mathrm{SO}_{4}^{2-}$ and $\mathrm{Na}^{+}$in cores $\mathrm{A}$ and $\mathrm{B}$, and illustrates the degree of spatial variability in the snow; these are typical of the ion profiles and comparative concentrations found in all the cores. The high concentrations in cores $\mathrm{A}, \mathrm{B}$ and $\mathrm{C}$ are associated with firn layers and ice lenses in the snow (Fig.3); these inhomogeneities in the snowpack channel the downward percolation of meltwater and may also inhibit the flow for a limited time. The two cores collected $7 \mathrm{~d}$ later (D and E) show much lower concentrations, particularly in the lower sections, (note $40 \mathrm{~cm}$ ablation) and reflect the complete ablation of the top $40 \mathrm{~cm}$ of snow and downward percolation of much of this meltwater accompanied by considerable removal of solute from the snowpack. However a simple fractionation mechanism is not sufficient to account for all the ion removal because solar radiation (direct melting) will only penetrate about a decimetre into the snow (O'Neill and Gray 1973). The percolating meltwater must be responsible for removing the ions lower down the cores, either by partial melting due to the temperature of the meltwater being above $0^{\circ} \mathrm{C}$ or possibly by a chromatographic effect between the snow crystals and the meltwater. In either case, these data strongly suggest that the majority of the solute in the snow is associated with the surface of the snow crystals where it can be easily removed.

\subsection{Field experiments - meltwater from the nest}

The time sequences of the concentrations of the four

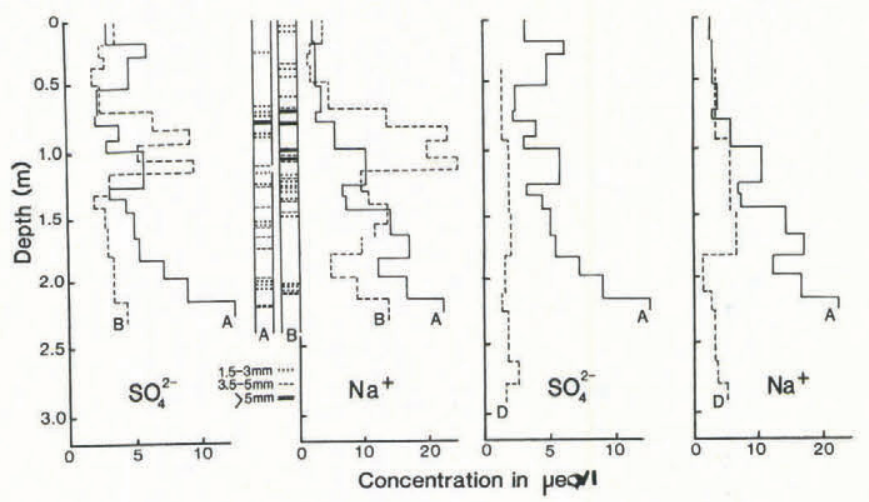

Fig.3. Ion concentration profiles for $\mathrm{SO}_{4}^{2-}$ and $\mathrm{Na}^{+}$in snow cores. Left: spatial variability between two cores, $A$ and $\mathrm{B}$, collected from positions $1 \mathrm{~m}$ apart on the same day $(8$ July), together with the positions of the ice/firn lenses in the cores. Right: temporal changes between core $\mathrm{A}$ and core $\mathrm{D}$ which was collected $7 \mathrm{~d}$ later.
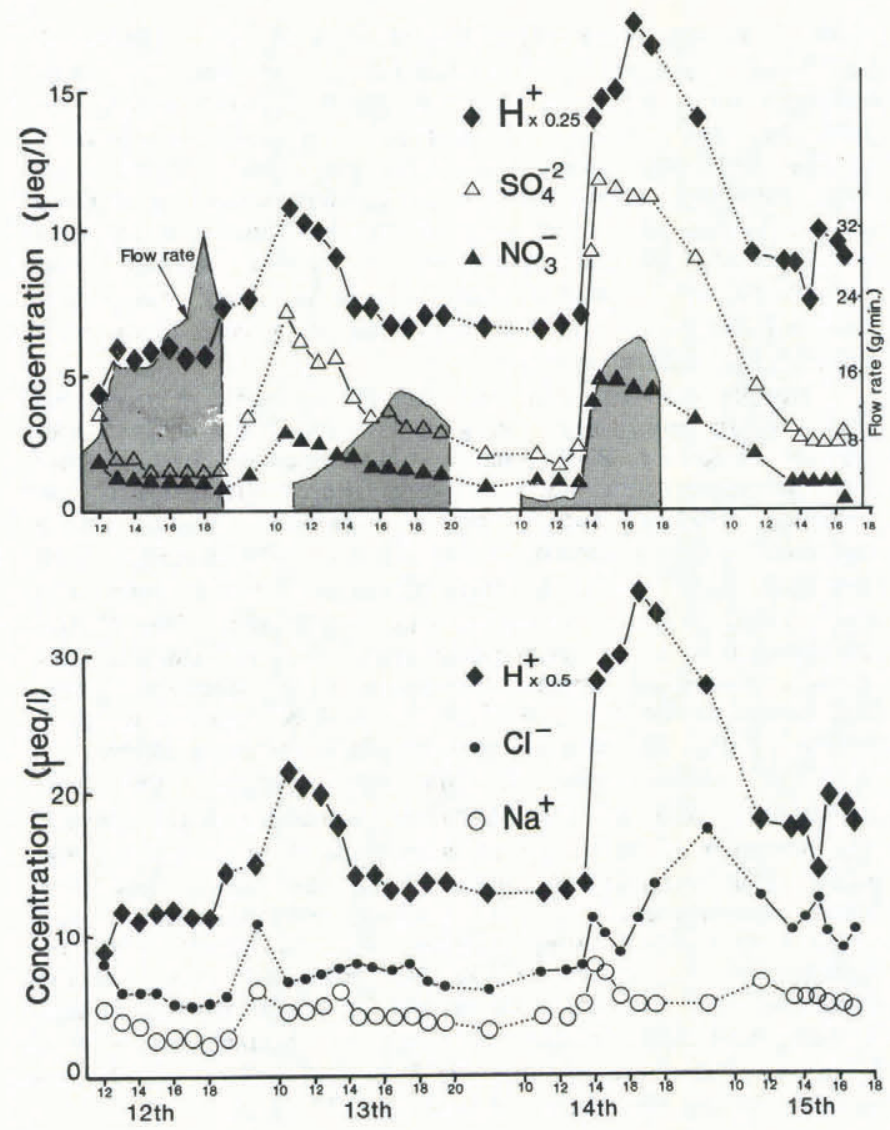

Fig.4. Meltwater concentrations for five major ions at the $1.8 \mathrm{~m}$ nest over the 4 days of the melt experiment. Time in hours on each day is shown. $\mathrm{H}^{+}$is shown on both graphs for comparative purposes but note the change in the ordinate scale.

major ions $\mathrm{Na}^{+}, \mathrm{SO}_{4}^{2-}, \mathrm{NO}_{3}^{-}$and $\mathrm{Cl}^{-}$plus $\mathrm{H}^{+}$are shown in Figure 4.

12 July: melting was initiated with the $275 \mathrm{~W}$ lamp $(10.50-11.40 \mathrm{~h})$ and, although solar radiation was strong resulting in a high ablation rate and a consequent high meltwater flow rate, the ionic concentrations remained almost constant throughout the day (Fig.4), due perhaps to the complete melting of the top 2 or $3 \mathrm{~cm}$ of snow by the lamp. The $\mathrm{pH}$ was 4.65 and the $\mathrm{SO}_{4}^{2-}: \mathrm{NO}_{3}^{-}$ratio was $1.7 \pm 0.13$. Concentrations of $\mathrm{Ca}^{2+}, \mathrm{Mg}^{2+}$ and $\mathrm{K}^{+}$were low, $<0.5 \mu \mathrm{eq} \mathrm{r}^{1}$ in total.

13 July: a clear, still day with strong insolation. $\mathrm{SO}_{4}^{2-}$ and $\mathrm{NO}_{3}^{-}$levels peaked at $11.00 \mathrm{~h}$, soon after measurements began, reaching 4 and 3 times the levels of the previous day, respectively. Their ratio increased to $2.35 \pm 0.18$ suggesting that $\mathrm{SO}_{4}^{2-}$ was being removed preferentially to $\mathrm{NO}_{3}^{-}$. The flow rate varied inversely to the concentrations of $\mathrm{SO}_{4}^{z^{-}-}$and $\mathrm{NO}_{3}^{-}$, showing the type of melt observed by Johannsen and Henriksen (1978). $\mathrm{Cl}^{-}$concentrations rose slowly to a maximum at mid-afternoon $(35 \%$ above that of 12 July) when the net radiation was at its most intense and the meltwater flow rate was close to its maximum. $\mathrm{H}^{+}$ closely followed the $\mathrm{SO}_{4}^{2-}$ and $\mathrm{NO}_{3}^{-}$variation, peaking (at a $\mathrm{pH}$ of 4.3$)$ at $11.00 \mathrm{~h}$. $\mathrm{Na}$ tended to follow the same pattern but also reflected the $\mathrm{Cl}^{-}$levels.

14 July: the morning was dominated by low cloud and drizzle, the precipitation amount $(<0.05 \mathrm{~mm})$ being too small for analysis. $\mathrm{Cl}^{-}, \mathrm{Na}^{+}$and $\mathrm{H}^{+}$were much the same as the previous evening but $\mathrm{SO}_{4}^{2-}$ and $\mathrm{NO}_{3}^{-}$had dropped back to their levels of 12 July. When the cloud cleared at $13.00 \mathrm{~h}$ meltwater concentrations immediately soared, $\mathrm{SO}_{4}^{2-}$ and $\mathrm{NO}_{3}^{-}$ values increasing five-fold while the $\mathrm{pH}$ dropped from 4.6 to 4.15 (a three-fold increase in $\mathrm{H}^{+}$) coinciding with a rapid increase in the flow rate (Fig.4). $\mathrm{Na}^{+}$doubled while $\mathrm{Cl}^{-}$once again showed a more sluggish and variable response.

15 July: a similar pattern to 13 July, except for the decrease in $\mathrm{Cl}^{-}$from the high values established the previous day. 
The overall pattern is one where $\mathrm{SO}_{4}^{2-}$ and $\mathrm{NO}_{3}^{-}$peak early in the daily melt, eluting quickly from the snowpack in the first meltwater fraction when flow rates were increasing. $\mathrm{H}^{+}$follows a similar pattern. Over the four days, $\mathrm{SO}_{4}^{2-}$ and $\mathrm{NO}_{3}^{-}$in the meltwater have a correlation of 0.98 , while the correlation coefficient between $\mathrm{SO}_{4}^{2-}$ and $\mathrm{H}^{+}$is 0.94 . The $99 \%$ confidence level for 30 degrees of freedom is 0.45 . The slowly eluting ions, $\mathrm{Na}^{+}$and $\mathrm{Cl}^{-}$, are well correlated with a coefficient of 0.74 (sea-salt is a significant constituent of maritime precipitation) but it is also clear from the correlation matrix (Table II) that a complex interrelationship exists between all five ions shown.

An average charge balance for different periods of the melt sequence (Table III) reveals a large excess of positive charge throughout the melt. Even assuming the error of 0.2 $\mathrm{pH}$ units suggested by McQuaker and others (1983) as common in field measurements of weak unbuffered systems such as these, there are too few anions, by a factor of more than 2, to balance the hydrogen ions. Further laboratory analyses have failed to locate a further major anion missed by our initial analyses and we conclude that the absolute accuracy of our field $\mathrm{pH}$ measurement must be in error by more than $0.2 \mathrm{pH}$ units $(\sim 0.5 \mathrm{pH})$. Errors of this magnitude in $\mathrm{pH}$ determinations are common as confirmed by the WMORPS (1978) study on the accuracy and reproducibility of rain-water $\mathrm{pH}$ and acidity. The relative $\mathrm{pH}$ values reported here were, however, repeatable and internally consistent, and show the general trends in $\mathrm{H}^{+}$.

The ion concentrations of the meltwater suggest an elution order of $\mathrm{SO}_{4}^{2-}, \mathrm{NO}_{3}^{-}, \mathrm{H}^{+}, \mathrm{Na}^{+}, \mathrm{Cl}^{-}$(similar to that found by Brimblecombe and others (1985) in their Scottish catchment) although it must be pointed out that some melting had occurred before this experiment and that this order may not be that of the first melt. $\mathrm{Ca}^{2+}, \mathrm{Mg}^{2+}$ and $\mathrm{K}^{+}$concentrations were close to the limits of detection and so have not been included in the elution order. The relative depletion of ions between cores collected on 8 and 15 July may be a better indicator of the order of preferential elution. These cores suggest the order $\mathrm{Ca}^{2+}, \mathrm{NO}_{3}^{-}, \mathrm{K}^{+}$, $\mathrm{Mg}^{2+}, \mathrm{SO}_{4}^{2-}, \mathrm{Na}^{+}, \mathrm{Cl}^{-}$(see Table I).

The charge contributions of the ions in the meltwater and the correlation coefficients between ions suggest (a) that at times of low concentrations more $\mathrm{H}^{+}$may be associated with the $\mathrm{Cl}^{-}$than with both $\mathrm{SO}_{4}^{2-}$ and $\mathrm{NO}_{3}^{-}$, while (b) at higher concentrations the additional $\mathrm{H}^{+}$may be dominantly associated with $\mathrm{SO}_{4}^{2-}$ and $\mathrm{NO}_{3}^{-}$. However, because of the difficulties in the absolute $\mathrm{pH}$ determinations and the lack of $\mathrm{NH}_{4}^{+}$measurements, these suggestions remain speculative.

\subsection{Melting experiment 1}

Melting was completed in a single sequence, with the final snow melting after $14 \mathrm{~h}$. Meltwater was collected in approximately $70 \mathrm{ml}$ samples from each of the two melt exits. The central exit is referred to as exit $C$ and the outer peripheral exit as exit $\mathbf{P}$ (Fig.2). Meltwater was collected from exit $P$ after $4.5 \mathrm{~h}$ but collection from exit $C$ began much later (after $6.8 \mathrm{~h}$ ). The rate of meltwater collection was variable, due partly to the problem of keeping the lamp a constant distance above the ablating snow surface and partly because the percolation of the meltwater through the snowpack is a non-uniform process, the water moving along preferred channels or ducts rather than down the full cross-section of pack as a water front (Colbeck 1972, Foster 1978, Hibberd 1984). The ionic concentrations for the anions and cations normalized to the bulk concentration at the beginning of the experiment are plotted in Figure 5 as a function of the total volume eluting through each exit. The time in hours is indicated on each graph so that the melt concentrations at any particular time can be compared. A total of 4.31 of meltwater were collected from exit $P$ and 3.51 from exit $C$

The meltwater concentrations from the two exits are strikingly different in several respects and suggest that the processes occurring within a snowpack during melting may be quite complex. Meltwater from exit $P$, which collects water from the sides of the cylinder, shows a steady decrease in the total ionic strength with time, reaching the bulk concentration after $9 \mathrm{~h}($ at $17.00 \mathrm{~h})$ and dropping to less than $25 \%$ of bulk after $13 \mathrm{~h}$. Meltwater from exit C, starting more than $2 \mathrm{~h}$ after exit $\mathrm{P}$ dropped to bulk at $7 \mathrm{~h}$ (at the third $70 \mathrm{ml}$ sample from this exit) and to $25 \%$ of bulk only $30 \mathrm{~min}$ later.

The initial order of elution of the ions from the two

TABLE II. CORRELATION MATRIX FOR FIVE MAJOR IONS IN MELTWATER

$\begin{array}{llllll} & \mathrm{Na}^{+} & \mathrm{Cl}^{-} & \mathrm{NO}_{3}^{-} & \mathrm{SO}_{4}^{2-} & \mathrm{H}^{+} \\ \mathrm{Na}^{+} & 1.00 & & & & \\ \mathrm{Cl}^{-} & 0.74 & 1.00 & & & \\ \mathrm{NO}_{3}^{-} & 0.58 & 0.42 & 1.00 & & \\ \mathrm{SO}_{4}^{2-} & 0.62 & 0.50 & 0.98 & 1.00 & \\ \mathrm{H}^{+} & 0.62 & 0.61 & 0.88 & 0.94 & 1.00\end{array}$

The $99 \%$ significance level for $30^{\circ}$ of freedom is 0.45 .

TABLE III. AVERAGE ION CONCENTRATIONS ( $\mu$ eq $\mathrm{r}^{-1}$ ) IN THE MELTWATER OVER DIFFERENT PERIODS

$\begin{array}{cccccccccc}\begin{array}{c}\text { Date } \\ \text { (July) }\end{array} & \begin{array}{c}\text { Time } \\ \text { (h) }\end{array} & \mathrm{SO}_{4}^{2-} & \mathrm{NO}_{3}^{-} & \mathrm{Cl}^{-} & \mathrm{Na}^{+} & \mathrm{H}^{+} & (\Sigma)^{-} & (\Sigma)+ & \text { Error } \\ 12 & & 1.8 & 1.1 & 6.2 & 3.2 & 24 \pm 12 & 9.1 \pm 0.3 & 27 \pm 12 & 18 \pm 12 \\ 13 & 10.00 \text { to } 14.00 & 6.0 & 2.6 & 6.7 & 4.6 & 43 \pm 20 & 15.3 \pm 0.4 & 48 \pm 20 & 32 \pm 20 \\ 13 & 15.00 \text { to } 19.00 & 3.4 & 1.5 & 7.2 & 3.7 & 28 \pm 13 & 21.1 \pm 0.3 & 32 \pm 13 & 20 \pm 13 \\ 14 & 10.00 \text { to } 13.00 & 1.9 & 1.0 & 7.1 & 3.9 & 26 \pm 12 & 10.0 \pm 03 & 30 \pm 12 & 20 \pm 12 \\ 14 & 14.00 \text { to } 18.0011 .6 & 4.9 & 10.1 & 6.7 & 60 \pm 27 & 26.6 \pm 08 & 67 \pm 27 & 40 \pm 27\end{array}$

$\mathrm{H}^{+}$error limits $\pm 0.2 \mathrm{pH}$ units.

Anion errors $\pm 2.5 \%$. Contribution of $\mathrm{Mg}^{2+}, \mathrm{Ca}^{2+}$ and $\mathrm{K}^{+}$was approximately $20 \%$ of that of $\mathrm{Na}^{+}$. 


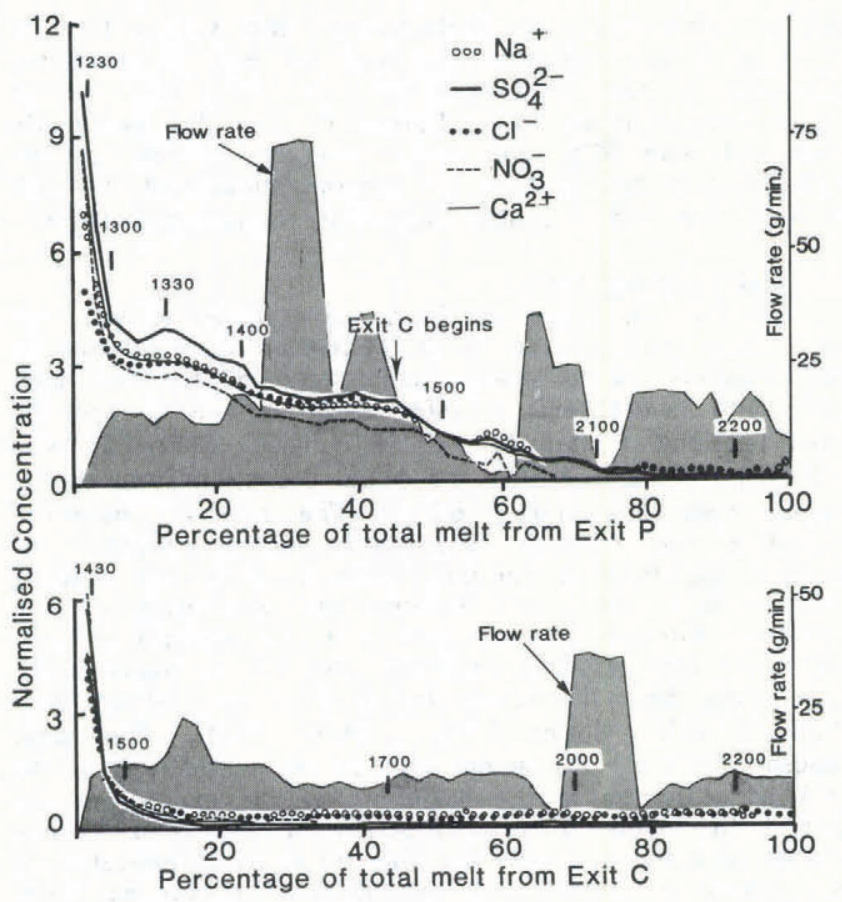

Fig.5. Variation in the concentrations of selected ions for the first melt experiment from exit $\mathrm{P}$ (upper) and exit $\mathrm{C}$ (lower). The heating lamp was switched on at $07.00 \mathrm{~h}$.

exits is given in Table IV together with rank orders of the eight major ions. The sequences show some differences, particularly for the elution of $\mathrm{NO}_{3}^{-}$, but both show rapid elution of $\mathrm{K}^{+}, \mathrm{Mg}^{2+}$ and $\mathrm{SO}_{4}^{2-}$ and slow elution of $\mathrm{Na}^{+}$and $\mathrm{Cl}^{-}$, a pattern similar to that recorded in the Norwegian field experiment. The difficulties in the measurement of $\mathrm{H}^{+}$ have precluded its inclusion in these two graphs but in the first melt fraction from both exits $\mathrm{H}^{+}$was less than in the bulk snow (by a factor of between 1 and 2).

\subsection{Melting experiment 2}

In order to reproduce some of the diurnal effects noted in the Norwegian field experiment a second melting experiment was performed. The snow used was from the same drift as the first experiment but during the storage period of nearly a year the snow had taken on a much more crystalline structure, consisting of small crystals about $1 \mathrm{~mm}$ in diameter, and had the texture of the snow/firn of ten encountered deeper in a snowpack in spring. Melting
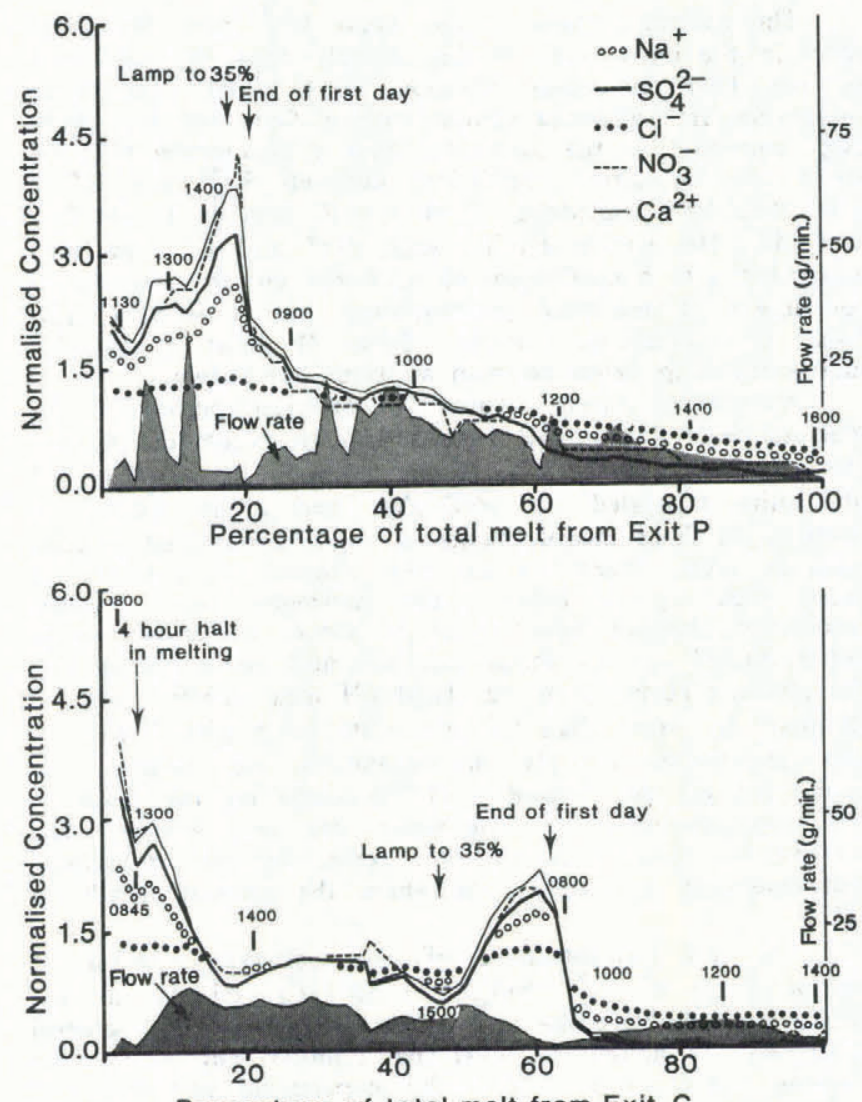

Percentage of total melt from Exit C

Fig.6. Variation in the concentrations of the same ions as shown in Figure 5 for the second melt experiment. Melting completed over 2 days, the lamp being switched on at $07.00 \mathrm{~h}$ each day. On the first day the lamp intensity was reduced to $35 \%$ at $15.00 \mathrm{~h}$ and switched off at $16.00 \mathrm{~h}$.

was completed over two days with a night between. The meltwater concentrations from the exits $\mathrm{P}$ and $\mathrm{C}$, normalized to that of the bulk snow, are shown in Figure 6. The first-melt concentrations are given in Table IV, along with their rank orders suggesting the sequence of preferential elution.

Water was collected first from exit C (as opposed to exit $P$ in experiment 1) within one hour of the heat lamp being switched on, but, after about $90 \mathrm{ml}$ had been collected, there was a hiatus of $4 \mathrm{~h}$ until $13.00 \mathrm{~h}$. From

\begin{tabular}{|c|c|c|c|c|c|c|c|c|}
\hline \multirow[t]{2}{*}{$\begin{array}{l}\text { Ion } \\
\text { species }\end{array}$} & \multirow{2}{*}{\multicolumn{2}{|c|}{$\begin{array}{l}\text { Normalized } \\
\text { 1st melt experiment } \\
\text { P } \quad \text { C }\end{array}$}} & \multicolumn{2}{|c|}{$\begin{array}{l}\text { concentrations } \\
\text { 2nd melt experiment }\end{array}$} & \multicolumn{2}{|c|}{$\begin{array}{l}\text { Rank elution } \\
\text { Ist }\end{array}$} & \multicolumn{2}{|c|}{$\begin{array}{l}\text { order } \\
2 \text { nd }\end{array}$} \\
\hline & & & P & C & & $\mathrm{C} \quad \mathrm{F}$ & & C \\
\hline $\mathrm{Na}^{+}$ & 6.9 & 4.5 & 1.7 & 2.4 & 6 & 5 & 6 & 6 \\
\hline $\mathrm{Mg}^{2+}$ & 8.7 & 4.9 & 2.2 & 4.2 & 3 & 4 & 2 & 1 \\
\hline $\mathrm{Ca}^{2+}$ & 8.2 & 4.0 & 2.3 & 3.7 & 4 & 6 & 1 & 3 \\
\hline $\mathrm{K}^{+}$ & 10.1 & 5.7 & 2.0 & 3.4 & 2 & 2 & 5 & 4 \\
\hline $\mathrm{SO}_{4}^{2-}$ & 10.2 & 4.9 & 2.1 & 3.3 & 1 & 3 & 4 & 5 \\
\hline $\mathrm{NO}_{3}^{-}$ & 8.2 & 6.1 & 2.2 & 4.0 & 5 & 1 & 3 & 2 \\
\hline $\mathrm{Cl}^{-}$ & 5.1 & 3.9 & 1.3 & 1.4 & 7 & 7 & 7 & 7 \\
\hline $\mathrm{H}^{+}$ & - & - & - & - & 8 & 8 & 8 & 8 \\
\hline
\end{tabular}


13.30 to $15.00 \mathrm{~h}$ concentrations were very close to that of the bulk, representing a period of equilibrium melting, i.e. total melting of the near-surface snow (from which most ions had already been removed) and initial preferential melting of snow further down the column. The intensity of the heat lamp was reduced to $35 \%$ at $15.00 \mathrm{~h}$ and the ionic strength of the meltwater increased (as the meltwater flow rate dropped) and exhibited the same preferential elution as at the beginning of the melt. The lamp was switched off at $16.00 \mathrm{~h}$ and collection ceased at $16.30 \mathrm{~h}$. During the next day melting continued, but after an initial sample with relatively high concentrations the meltwater collected at exit $\mathrm{C}$ had very low concentrations (with the exception of $\mathrm{Na}^{+}$and $\mathrm{Cl}^{-}$, which stabilized at 30 and $40 \%$ of bulk respectively). In total, 3.21 of meltwater were collected from exit $\mathrm{C}$.

Exit $P$ showed quite a different pattern with concentrations increasing from $11.30 \mathrm{~h}$, when the first melt was collected, to $15.00 \mathrm{~h}$ when collection stopped. The order of elution remained remarkably constant throughout the first day and was similar to that of the first-melt fraction. In contrast to exit C, there was very little melt collected from $P$ when the intensity of the lamp was decreased. During the following day concentrations gradually decreased although there was an extended period from 09.00 to $11.00 \mathrm{~h}$ when they were close to those of the bulk.

\section{CONCLUSIONS}

The field and laboratory experiments show that fractionation (Johannssen and Henriksen 1978) and preferential elution (Davies and others 1982) are important processes in determining the concentration of meltwater run-off from a melting snowpack and that the simple analysis of the chemical composition of bulk snow cannot be directly used as a surrogate for meltwater, either for absolute or for relative ion concentrations. However, the patterns of preferential elution and fractionation exhibited in these experiments may enable some conclusions to be drawn about the likely meltwater composition if the bulk snow composition is known (both chemically and physically) although more experiments are needed to verify the results shown here.

The order of preferential elution of the ions in a snowpack is very clear in some respects and much more confused in others. $\mathrm{Cl}^{-}$is consistently the most slowly eluted ion and $\mathrm{Na}^{+}$is almost as slow. This is interpreted as being due to the importance of sea-salt as condensation nuclei in the atmosphere; much $\mathrm{Cl}^{-}$and $\mathrm{Na}^{+}$will be trapped in the interior of ice crystals during freezing and only mobilized slowly with bulk melting. If the order of preferential elution is due predominantly to the position of the ions within, or attached to the outside of, the snow crystal (or, in the case of older snow or firn, to the ice crystal) then the order will vary depending on the atmospheric history of the snow. It will depend on the initial condensation and freezing of water vapour in the air-mass, and on the subsequent scavenging during transport and during the precipitation processes. Ion species associated with atmospheric pollution such as $\mathrm{SO}_{4}^{2-}$ and $\mathrm{NO}_{3}^{-}$could be expected to be attached to the surface of the snow crystals and thus be readily available for removal early in the melt process. In addition to this simple physical view of fractionation and of the phenomenon of preferential elution, the chemical properties of the individual ions will influence the ease with which they can be removed from the snowpack but it is not possible from the simple experiments described here to differentiate between the relative importance of the physical and chemical processes.

The position of $\mathrm{H}^{+}$in these experiments is uncertain. Although the relative $\mathrm{H}^{+}$concentrations are well-defined, the absolute accuracy of the measurements is not. The field data suggest that the $\mathrm{H}^{+}$ion is quite closely associated with the $\mathrm{SO}_{4}^{2-}$ and the $\mathrm{NO}_{3}^{-}$ions and is eluted with these ions, although how much melting had occurred before these samples was unknown. The laboratory experiments show $\mathrm{H}^{+}$ as being a slowly eluted ion, in contrast to the field data and at variance with the results of other studies (Davies and others 1982, Brimblecombe and others 1985).

\section{REFERENCES}

Brimblecombe P, Tranter M, Abrahams P W, Blackwood I, Davies T D, Vincent C E 1985 Relocation and preferential elution of acidic solute through the snowpack of a small, remote, high-altitude Scottish catchment. Annals of Glaciology 7: 141-147

Colbeck S C 1972 A theory of water percolation in snow. Journal of Glaciology 11(63): 369-385

Davies T D, Vincent C E, Brimblecombe P 1982 Preferential elution of strong acids from a Norwegian ice cap. Nature 300(5883): 161-163

Foster P M 1978 The modelling of pollutant concentrations during snow melt. Leatherhead, Surrey, Central Electricity Research Laboratories (Laboratory Note RD/L/N 46/78)

Hagen A, Langeland A 1973 Polluted snow in southern Norway and the effect of the meltwater on freshwater and aquatic organisms. Environmental Pollution 5: 45-57

Hibberd S 1984 A model for pollutant concentrations during snow-melt. Journal of Glaciology 30(104): 58-65

Johannessen M, Henriksen A 1978 Chemistry of snow meltwater: changes in concentration during melting. Water Resources Research 14(4): 615-619

Leivestad H, Muniz I P 1976 Fish kill at low pH in a Norwegian river. Nature 259(5542): 391-392

McQuaker N R, Kluckner P D, Sandberg D K 1983 Chemical analysis of acid precipitation: $\mathrm{pH}$ and acidity determinations. Environmental Science and Technology 17: 431-435

National Research Council of Canada 1981 Acidification in the Canadian aquatic environment: scientific criteria for assessing the effects of acidic deposition on aquatic ecosystems. Ottawa, National Research Council of Canada (Publication 18475 196)

O'Neill A D J, Gray D M 1973 Solar radiation penetration through snow. International Association of Hydrological Sciences Publication 107 (Symposium of Banff 1972 Role of Snow and Ice in Hydrology) Vol 1: 227-241

WMORPS 1978 World Meteorological Organization second analysis on reference precipitation samples. Geneva, WMO 